\title{
Contemplative Practice: Philosophy, Pedagogy, and Science
}

\author{
Christopher Miller
}

Correspondence:

chpmiller@ucdavis.edu

University of California, Davis, USA
Welcome to a special issue of the International Journal of Dharma Studies. Here readers will find five articles that approach contemplative practice from various philosophical, pedagogical, and scientific perspectives. The diverse contents presented here will likely interest a broad range of readers including scholars, students, and practitioners alike. Taken as a whole, our authors' contributions amplify the relevance of contemplative practices during our shared times of political, social, and environmental uncertainty and provide multiple pathways and methods for understanding, disseminating, and appreciating such practices.

In the first two articles, Loriliai Biernacki and Kusumita Pedersen present contemplative practice from within dharma traditions. From a Tantric perspective, Biernacki's piece shows us how a nuanced understanding of the imagination can be used in contemplative practice to help us remedy the disintegrated, mechanistic world produced by the Cartesian mind-body split. Specifically, Biernacki differentiates the concepts of imagination expressed through bhāvana and vikalpa as found in the work of Abhinavagupta and Utpaladeva, showing us how bhāvana produces an integral experience of the mind and body in everyday life (vyavahära), as opposed to the fragmented reality that vikalpa inevitably perpetuates.

Moving into the contemporary period, Kusumita Pedersen shares Sri Chinmoy's approaches to contemplative practice and the achievement of self-realization. Combining selections from his vast textual corpus with her many years of personal practice with Chinmoy, Pedersen skillfully delineates her guru's spiritual path while providing us with ongoing context to help us understand the significant life experiences and influences that shaped his teachings. As we proceed through Pedersen's article, we discover the prescription for contemplative practices that gradually liberate while nevertheless remaining socially-engaged and applied in the midst of everyday life. Together, Pedersen and Biernacki present contemplative practices oriented toward transforming the worlds in which we live.

The second two articles in this series, one by Andy Fort and the other by Jane Brucker and Christopher Chapple, address contemplative pedagogy and address the question, "How and why should we use contemplative practices as pedagogical techniques in the university classroom?" This is a question taken up at length in volumes such as Meditation and the Classroom (Simmer-Brown and Grace 2011), and reflects a response to a trend that has been developing in universities across the United States. In this regard, Andy Fort of Texas Christian University (TCU) argues that

(c) The Author(s). 2016 Open Access This article is distributed under the terms of the Creative Commons Attribution 4.0 International License (http://creativecommons.org/licenses/by/4.0/), which permits unrestricted use, distribution, and reproduction in any medium, provided you give appropriate credit to the original author(s) and the source, provide a link to the Creative Commons license, and indicate if changes were made. 
contemplative studies programs are in harmony with and even enhance the goals of a classic liberal arts education. Fort shares the history of the development of TCU's own contemplative studies program, providing a potential template for how one might develop such a program at their home institution. With much experience in this arena, Fort also problematizes the use of contemplative studies in a religious studies curriculum and offers useful resources for exploring existing scholarly debates. Acknowledging the issues, Fort presents a convincing and optimistic argument that speaks to the pedagogical potential for using first-person inquiry, an opportunity that contemplative practices offer for today's university students who, more and more, desire such complementary educational experiences in their early years of formation.

Moving to Loyola Marymount University (LMU), Chapple and Brucker articulate LMU's Engaged Learning process as taught in their respective undergraduate courses. Brucker, a professor of studio arts, describes the awareness techniques she uses with her students to cultivate their creative process. Chapple, a professor of comparative theology, shares the core elements of his undergraduate Buddhism course curriculum, demonstrating the ways in which his students are encouraged to reflect upon Buddhist philosophy, ethics, and meditative practice as they engage in service projects and with the local ecology in the Los Angeles area. As a whole, Fort, Brucker, and Chapple provide reflections grounded in many years of experience that add to the growing literature speaking to the benefits and challenges of including contemplative practices in university curriculums.

Though we began this introduction with a brief mention of the mind-body problem and the potentially mechanistic outlook such a worldview produces, we would, nevertheless, be at a loss if we were to neglect the fascinating insights that science provides with regard to meditation and breath practices. Thus, while acknowledging that premodern cartographies of the body provide us with alternative ways of understanding our embodiment, physiologist Jeremy Wasser concludes this issue with a convincing case for the inclusion of anatomical and physiological perspectives in our studies of contemplative practices. Providing an accessible explanation of the human anatomy during various phases of meditation and breath work, Wasser leaves his reader reenchanted with the body and its capacity to intentionally create the space for that something beyond, however variously conceived.

We hope that you enjoy this issue and will circulate its contents amongst your colleagues and friends who share contemplative interests. We also thank our anonymous peer reviewers for their careful efforts toward fine-tuning each of the articles herein.

Competing interests

The author declares that he has no competing interests.

Received: 5 October 2016 Accepted: 5 October 2016

Published online: 24 October 2016 